\title{
ENTREVISTA A JAUME CARBONELL SEBARROJA
}

\section{Interview with Jaume Carbonell Sebarroja}

\section{Antoni Tort Bardolet" y Antón Costa Rico** \\ Fecha de recepción: 19/01/2016 • Fecha de aceptación: 21/01/2016}

Resumen: Jaume Carbonell es un muy reconocido pedagogo, periodista y docente universitario. Cofundador, redactor y director durante casi cuatro décadas de la Revista Cuadernos de Pedagogía, puesto del que se jubiló en el 2012. En la presente entrevista se procura recorrer su trayectoria personal y profesional en calidad de analista y actor destacado de la educación contemporánea en España. También se abordan los principales temas de la agenda educativa actual y se analizan las reformas acaecidas en el sistema educativo español: sus logros, retrocesos y contradicciones. Asimismo, se discuten los retos y posibilidades en relación con las capacidades de los diferentes agentes educativos para implementar procesos de innovación profundos y sostenibles.

Palabras clave: Política educativa. Sistema educativo. Innovación educativa. Autonomía escolar. Formación de maestros.

Abstract. Jaume Carbonell is a renowned educator, journalist, and university lecturer. He was also the editor and director of the journal Cuadernos de Pedagogía for almost four decades before retiring from this position in 2012. In this interview, we seek to explore his personal and professional career as an analyst and prominent actor in the panorama of contemporary education in Spain. The text analyzes the main topics of the current educational agenda as well as the scope of the reforms undertaken in the Spanish educational system. Its achievements, setbacks and

\footnotetext{
* Universitat de Vic - Universitat Central de Catalunya. Facultad de Educación, Traducción y Ciencias Humanas. Dpt. de Pedagogia. C/ Sagrada Familia, 7. 08500 Vic. Barcelona. España. antoni.tort@uvic.ca

** Universidade de Santiago de Compostela. Facultade de Ciencias da Educación. Teoría da Educación, Historia da Educación e Pedagoxía Social. Campus Vida. 15782 Santiago de Compostela. España. anton.costa@usc.es
} 
contradictions are all discussed. The interview then goes on to explore the challenges and opportunities relating to the capacities of different education agents to implement profound and sustainable innovations.

Keywords: Education policy. Education system. Educational innovation. School autonomy. Teacher training.

Jaume Carbonell i Sebarroja (Barcelona, 20 de noviembre de 1947) ha sido durante largos años director de la revista Cuadernos de Pedagogía, nacida en el año 1975, de la que formó parte ya desde el primer número, inicialmente como Secretario de redacción, bien pronto como Subdirector y más tarde Director. Junto a Fabricio Caivano en una primera época y después en solitario, Jaume Carbonell, junto a la redacción y sus corresponsalías, ha convertido Cuadernos de Pedagogía en una revista de referencia para el mundo educativo en España y también en Latinoamérica.

Desde esta atalaya no solo ha sido un observador y testigo privilegiado de lo que ha sucedido en la educación española en los últimos cuarenta años, sino que su persona y la revista se han convertido en actores directos e influyentes de los cambios educativos vividos. Cuadernos de Pedagogía ha ejercido de voz y altavoz de todo un patrimonio pedagógico hecho de experiencias escolares, proyectos, ideas, historias de vida e inquietudes. Un repaso a las editoriales mensuales (once números por año) de esta publicación, escritos por Jaume Carbonell, nos muestra este doble papel de actor y observador, tanto de las amplias reformas, como de las pequeñas y profundas trasformaciones. Atento a las políticas educativas, pero también a las innovaciones pedagógicas y a las vicisitudes y realizaciones en las aulas. Estudioso y buen conocedor de la historia de la educación y, al mismo tiempo, perspicaz analista a la hora de intuir los nuevos horizontes de la pedagogía. En consecuencia, Jaume Carbonell forma parte, como protagonista y como acompañante, de nuestro escenario educativo: de la pequeña escuela rural a la universidad, desde foros ilustres junto a altos responsables políticos a coloquios informales en humildes pero impagables asociaciones y entidades de base. Sus minúsculas y, sin embargo, prodigiosas agendas, repletas de contactos, podrían dar muchas claves sobre la historia reciente de la educación en España. Como se ha señalado en alguna ocasión, Jaume Carbonell es de las pocas personas que ha conocido de cerca a todos los ministros y ministras de educación que ha tenido España en treinta años. 
Exactamente dieciocho ministros, entre la fundación de Cuadernos (año 1975) y su jubilación como director de la revista (año 2012). De todo ello deviene la oportunidad de la presente entrevista, ligada al monográfico «Las reformas y las política educativas» de Historia y Memoria de la Educación.

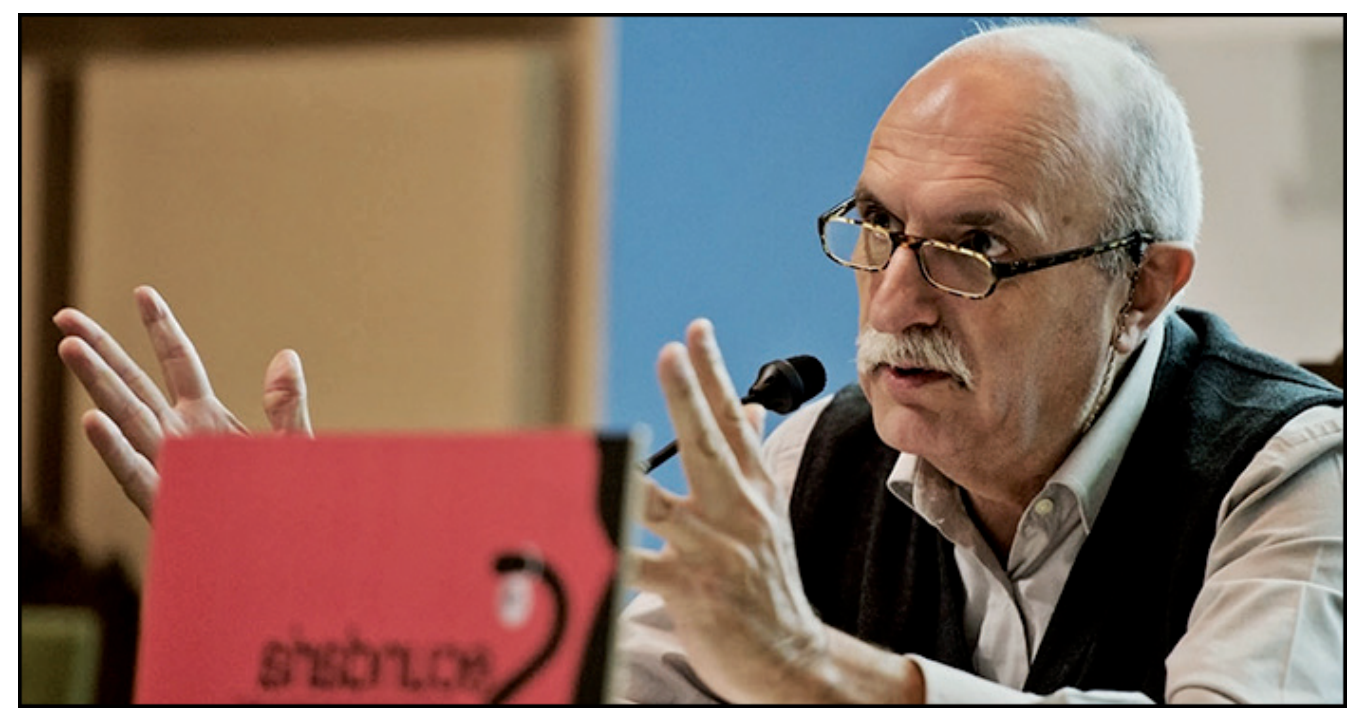

Jaume Carbonell. (Conferencia en Santander, 2011).

Con todo y ello, no sería exacto reducir la personalidad y trayectoria de Jaume Carbonell a su labor al frente de la revista Cuadernos de Pedagogía. Como en otros casos relevantes de nuestra historia educativa, como podrían ser la Revista de Pedagogía de Lorenzo Luzuriaga o el Boletín de la Escuela Moderna de Ferrer y Guardia, la revista Cuadernos de Pedagogía de Caivano y Carbonell ejerció durante décadas un destacado papel en cuanto al impulso de la edición de libros, bien con un sello propio, o bien a través de colecciones específicas de editoriales próximas en cuanto a la filosofía de trabajo: es el caso, entre otras, de "Laia», «Paidós», «Icaria», «Reforma de la Escuela» o «Nuestra Cultura». En ellas, Jaume Carbonell ejerce de editor y asesora colecciones. También ha ejercido como crítico de libros para la prensa generalista y especializada en catalán y en castellano. Él mismo es autor de una extensa obra publicada en libros, que empieza con un estudio exhaustivo, L'Escola Normal de la Generalitat: 1931-1939, sobre lo que significó esta institución educativa de vanguardia en la época repu- 
blicana donde habían estudiado sus padres y que termina, hasta la fecha, con un libro sobre la educación actual: Pedagogías del siglo XXI: alternativas para la innovación educativa. Así pues, entre el pasado y el futuro de la educación, Jaume Carbonell cuenta, individualmente y con otros colegas, con una amplia producción: análisis pedagógicos y sociológicos de la realidad educativa, como La escuela: entre la utopía y la realidad: diez temas de sociología de la educación, La reforma educativa a lo claro, La aventura de innovar: el cambio en la escuela, El sistema educativo: una mirada crítica, La educación y su representación en los medios y tantos otros. Carbonell también ha publicado crónicas y retratos de escuelas, en un género que también tiene precedentes ilustres, a mitad de camino entre el libro de viajes, la crónica periodística y la descripción antropológica. Ha sido un viajero tenaz, lo que le ha permitido observar centenares de escuelas y dialogar con miles de maestros. Algunos ejemplos de ello son: La vida escolar en un curso, cosas que no siempre se explican, Viaje por las escuelas de Cantabria, Viaje por las escuelas de Aragón y Viaje por las escuelas de Asturias. Es autor o coautor de antologías y de presentaciones e interpretaciones históricas referidas a grandes pedagogos de nuestra historia reciente (Makarenko, Dewey, Cossío, Freinet o Ferrer y Guardia). También es coautor de obras resultantes de investigaciones llevadas a cabo junto al profesorado de todos los niveles e investigadores universitarios, como los libros Aprendiendo de las innovaciones en los centros, La perspectiva interpretativa de investigación aplicada a tres estudios de caso, o Magrebies en las aulas. Municipio, escuela e inmigración: un caso a debate. Y, es que, además de su ocupación principal en Cuadernos de Pedagogía, Carbonell participa activamente, en diferentes épocas, en proyectos y grupos de investigación de diversas universidades. Su triple condición de sociólogo, de pedagogo y de periodista se ha traducido siempre en unos libros y en unos artículos, numerosísimos, bien escritos, claros y atentos a la actualidad.

Jaume Carbonell ha mantenido, además, una larga y fructífera colaboración como docente en la formación del profesorado en la Universitat de Vic (Barcelona), primero en la Escuela de maestros y, después, en la Facultad, de dicha universidad, donde leyó su lección de jubilación en 2012. Formó parte, como miembro, del Consejo Escolar del Estado entre 1983 y 1988. Su presencia ha sido constante en los medios de comunicación y ha sido un infatigable conferenciante en foros de todo tipo y condición de toda la Península y en Latinoamérica. En el momento de su jubilación, Cuadernos 
de Pedagogía le dedicó un número extraordinario ${ }^{1}$ y se publicó también un liber amicorum en el que casi una treintena de personas del ámbito de la pedagogía del Estado español rendían homenaje a su trayectoria. ${ }^{2}$

Actualmente jubilado, pero sin dejar de trabajar, escribe con regularidad en El diari de l'educació y colabora con otros medios de comunicación. Imparte conferencias y sigue viajando, quizás con menos asiduidad, pero con la misma curiosidad y pasión de siempre. Y tiene un poco más de tiempo para dar un paseo por la playa, darse un buen baño de mar y estar con su hija Sara, en Montgat, donde reside y donde nos recibe para iniciar esta entrevista.

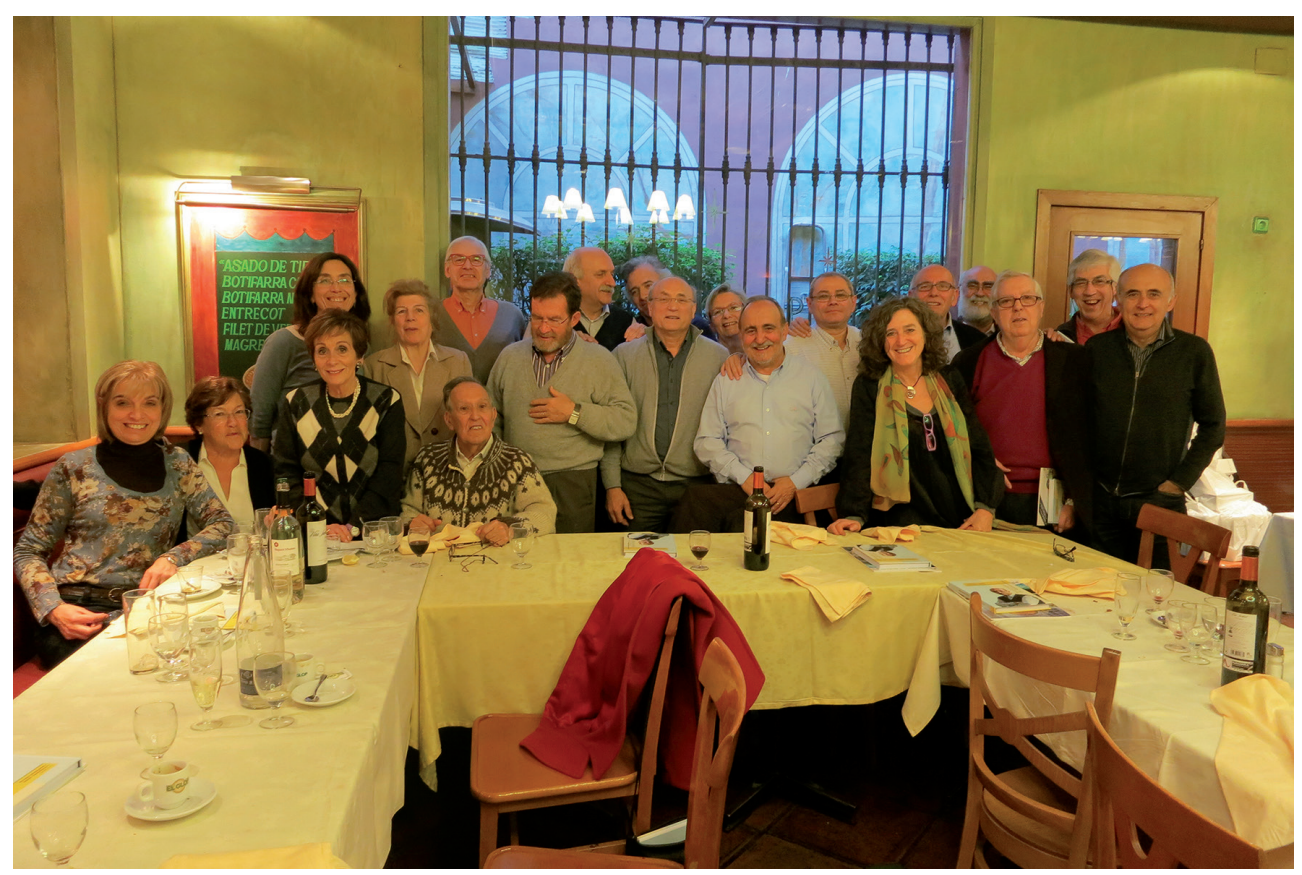

Celebración con motivo de su jubilación, junto a un nutrido grupo de pedagogos y pedagogas.

\footnotetext{
1 «Jaume Carbonell. El viaje continua», Cuadernos de Pedagogía, n. ${ }^{\circ}$ especial (2012): 1-78

2 AA. VV, Una propuesta de reconocimiento y amistad. (Homenaje a Jaume Carbonell), (Barcelona: Edición privada, 2012). El libro cuenta con las aportaciones, por este orden, de: Francesc Imbernon, Jaume Martínez Bonafé, Jesús Jiménez, Antonio Viñao, Pedro Badía, Luis Otano, Pepe Contreras, Pilar Benejam, Ángel I. Pérez Gómez, Mariano Fernández Enguita, Julio Rogero, Antón Costa Rico, Nieves Blanco, Juana M. ${ }^{a}$ Sancho Gil, Rafael Porlán, Fernando Hernández, Antoni Tort, Alejandro Tiana, Jose Gimeno Sacristán, Jurjo Torres, Joan Domènech, Daniel Jover, Pere Solà, Jordi Monés, Cinta Vidal, Mariona Ribalta, Luis Mari Álvarez y Jesús Palacios.
} 
Si pudiéramos visualizar tu trayectoria al frente de Cuadernos de Pedagogía se nos aparecerían centenares de escuelas e institutos que has visitado a lo largo de toda tu vida personal y profesional. Pero, ¿cómo era la escuela a la que fuiste de niño? Has explicado en diferentes entrevistas y conferencias que no fuiste precisamente un alumno ejemplar... ¿Cómo recuerdas tu infancia y tu escolaridad?

Yo viví los años duros de la escuela franquista, la escuela-cuartel del guardar filas, izar bandera y cantar himnos guerreros en la que mi infancia se fragmentaba entre el alumno Jaime y el niño Jaume, porque el catalán estaba proscrito en la escuela de los años cincuenta. En clase, éramos noventa alumnos que formábamos parte de al menos tres grupos diferentes: el de los afortunados, unos pocos que íbamos a cursar el bachillerato y ocupábamos la primera fila; el del grupo mayoritario, que recibía la cultura general de primaria hasta los doce años - al final de curso venían a contratarlos los responsables de recursos humanos de la SEAT-, y los que hacían comercio y taquigrafía y no paraban de teclear en las viejas máquinas Underwood. A propósito, ¿quién ha dicho que la diversidad la introdujo la LOGSE
[Ley Orgánica General del Sistema Educativo de 1990]? Yo tuve graves problemas de lectoescritura, pasé por la consulta de un psicólogo y al final cambié varias veces de centro escolar. Pero aquellas carencias desaparecieron con el paso del tiempo. Y, paradojas de la vida, desde hace casi cuarenta años vivo de la lectura y de la escritura. Es una lección que no deberíamos olvidar: una cosa es que se juegue con las cartas marcadas de un diagnóstico demoledor, y otra muy diferente es poder actuar con las cartas bien mezcladas y bien jugadas, para tener todas las opciones abiertas en la partida de la vida.

De todas formas, con la perspectiva que da el tiempo valoro extraordinariamente la educación que recibí en tres ámbitos no escolares: la familia, la calle y el escultismo. En casa éramos siete hermanos y, en consecuencia, vivíamos un proceso de socialización absolutamente distinto al de la escuela por el hecho de que mis padres se habían formado, como futuros maestros, en la Escuela Normal de la Generalitat republicana. Como ejemplo, recuerdo que mi padre organizaba, algunos domingos por la tarde, sesiones de títeres para los niños del vecindario, que convocábamos a través de las azoteas. Yo le ayudaba a construir los títeres de corcho y los decorados para el guiñol. Sospecho que de aquí me vino 
la afición al teatro, al que acudía con frecuencia con mi madre y mi padre. La calle era nuestra; era un entorno colonizado por la infancia, del que nos habíamos apropiado absolutamente; allí practicábamos toda clase de juegos, conocidos e inventados, con las travesuras pertinentes. Y nos contábamos historias y aventuras sobre todo en las noches de verano. Jugábamos a fútbol con cualquier pelota, improvisando, en cualquier lugar. El escultismo fue una tabla de salvación donde viví otra infancia. Aprendí a desarrollar la iniciativa, la autonomía, y diversas habilidades manuales y expresivas, a conocer la ciudad y, sobre todo, a descubrir y respetar la naturaleza. Fue un mundo trufado de oportunidades y posibilidades aunque - todo hay que decirlo- quizás con un exceso de rituales competitivos y militaristas.

Si sigo avanzando en mi escolaridad, debo decir que el bachillerato superior lo estudié en el Instituto «Isabel de Villena» de Barcelona, con docentes que también se habían formado en las instituciones de la Generalitat de la época republicana. Recuerdo especialmente dos grandes profesoras, personalidades de gran relieve: Maria Aurèlia Capmany, escritora y política socialista (llegó a ser regidora de cultura del Ayuntamiento de Barcelona) y Carme Serrallonga, traductora. Las dos for- maban parte de un entorno cultural e intelectual de alto nivel, amigas de escritores, de actores de teatro, etc. No seguían el programa oficial de sus respectivas asignaturas pero despertaron en nosotros el deseo de conocer, de leer, de frecuentar el teatro, de viajar. En el caso de Carme Serrallonga, como tenía problemas para caminar, muchas veces las clases las hacíamos en su domicilio particular, un pequeño paraíso repleto de libros y otros objetos artísticos.

- Como ya se ha comentado, tanto tu padre Pere, como tu madre, Isabel, se formaron como futuros maestros en la "Escola Normal» durante la República, una institución de gran prestigio con un claustro de profesores extraordinario. La represión y depuración que llegó con la victoria franquista impidió que tus padres pudieran ejercer nunca de maestros, pero el magisterio ha sido siempre una cuestión central y muy presente en tu entorno familiar. Un hermano tuyo ha sido maestro. También tu mujer. ¿Tu interés por la pedagogía viene por los antecedentes familiares? y, en cualquier caso, ¿cómo fue tu paso por la universidad?

En realidad yo siempre quise ser capitán de barco. Aparte de estas fantasías infantiles que se esfumaron con el tiempo, pero que me dejaron la inquietud por los viajes, 
yo entré en la Facultad y en los estudios de Filosofía y Letras en la Universidad de Barcelona (la única existente en Cataluña en aquellos momentos) teniendo serias dudas entre profundizar en las lenguas románicas, pues me gustaba mucho leer y todo lo relacionado con la literatura, u optar por la pedagogía, pues tenía experiencias en el escultismo, en el ámbito de las colonias escolares y el tiempo libre y esto me gustaba, me enganchaba. Seguramente ello hizo que me inclinara por la pedagogía. No fue tanto por la historia de mis padres porque curiosamente lo de mis padres lo descubro, digamos, más tarde. Sabía vagamente algo de su historia pero no me condicionó en la elección de lo que sería el segundo ciclo universitario o especialidad. Me hubiera gustado estudiar humanidades en un sentido amplio. Creo que tengo unas carencias que habría subsanado con unos estudios con una fuerte cultura humanística, un poco de ciencia, psicología, pedagogía... Pero entonces no se podía hacer esto y, a mí, tener que elegir en tercero no me gustó. Debo añadir que mi actividad como estudiante de pedagogía fue nefasta, en buena parte porque en el primer año de especialidad me expedientaron por mi militancia política en el entonces ilegal Sindicato de Estudiantes del que yo era delegado: me expulsaron de la universidad durante tres años $y$, en consecuencia, estuve apartado todo ese tiempo. Cuando reemprendí los estudios, ya lo hice como estudiante «libre»y, por lo tanto, mi vida universitaria se redujo a su mínima expresión. Pero, por otro lado, tengo que decir que estando fuera de la universidad aproveché muchísimo el tiempo, frecuentaba librerías, consultaba, leía, etc. La actividad política me ayudó muchísimo en mi formación. Se puede decir que aprendí a escribir confeccionando octavillas y otros papeles de carácter político. Tenía que ceñirme a un espacio concreto $\mathrm{y}$ los mensajes tenían que ser breves y comprensibles. También redactaba fichas para el cine fórum que hacíamos en el barrio y que fue especialmente relevante en mi formación. Era una actividad que se desarrollaba en un local parroquial en el barrio barcelonés de Horta. Queríamos concienciar, sensibilizar con nuevas ideas. Estamos hablando de finales de los sesenta y yo tenía unos diecinueve años. El cine fórum se convirtió en un espacio de libertad extraordinario, lleno de expresión crítica, de pluralismo, de aprendizaje de lo que es debatir, argumentar. Venían personas de gran valía, profundos conocedores del mundo del cine y discutíamos hasta las tantas de la madrugada. Era apasionante. Se convirtió en una escuela de formación muy 
importante: a partir del cine, aprendías algo del llamado séptimo arte y aprendías qué pasaba en el mundo y qué ocurría aquí. Al cabo de dos años, un día nos llama el rector de la parroquia y nos dice: "esto se ha acabado, esto es un centro parroquial y en todas las películas y debates sólo se habla de antifranquismo, de capitalismo e imperialismo...». El hombre tenía toda la razón.

El mundo de la universidad me quedó, pues, un poco lejos, pero mantuve buenas amistades, entre ellas, otro delegado de curso, el hoy reputado ensayista Rafael Argullol, catedrático de Estética en la Universitat Pompeu Fabra de Barcelona. Y poco a poco en el ámbito del activismo social barcelonés fui conociendo otras personas relevantes, amigos y amigas con quienes compartíamos inquietudes políticas y sociales. Una de ellas fue Josep M. Huertas Clavería, gran periodista y mejor persona con quien (junto a su mujer la jueza Araceli Aiguaviva) mantuve una larga amistad a lo largo de toda su vida. A la manera del geógrafo y pedagogo Pau Vila que decía que la geografía se hacía con los pies (caminando, yendo de excursión, paseando...), Huertas explicaba que el periodismo de verdad era el que gastaba muchas suelas de los zapatos. Un periodismo, pues, de pisar las calles, de hablar con la gente. Sus consejos me sirvieron de mucho en mi trabajo posterior en Cuadernos de Pedagogía. Fueron justamente Argullol y Huertas, por canales diferentes, quienes me hicieron saber que se ponía en marcha una revista de educación, que sería Cuadernos..., donde empezaría a trabajar ya desde el primer número que salió en enero de 1975.

Pero mi interés por la pedagogía se había acrecentado ya un poco antes, sobre todo por mi asistencia a las «Escoles d'Estiu» que organizaba la asociación de maestros y maestras «Rosa Sensat». En aquellos momentos, esta institución era el puesto más avanzado en la renovación pedagógica de todo el Estado español. Recuerdo que en la primera edición de la «Escola d'Estiu» se llevó a cabo una reunión con gente de toda España y lo rememoro como una situación especialmente estimulante y enriquecedora. Por otra parte me proporcionó muchos contactos y relaciones personales. Para Cuadernos las Escuelas de Verano acabarían siendo, sin duda alguna, un puntal y un referente pedagógico esencial. Así pues, tras mi paso poco glorioso por las aulas universitarias empecé a descubrir otra concepción de la infancia y de la educación, radicalmente distinta, gracias a las maestras de "Rosa Sensat». 
Ello coincidió con el hecho de que empecé a profundizar en la historia reciente de la educación en nuestro país, a través de mis conversaciones con mis padres, que me contaron su experiencia republicana como alumnos de la Escuela Normal de la Generalitat y de sus prácticas en los grupos escolares más innovadores. Ellos me alentaron a que iniciara una investigación, que se convirtió en mi primer libro, entrevistando a una cuarentena de antiguos alumnos de dicha Normal. Una ayuda de la Fundación «Jaume Bofill» me permitió llevar a cabo dicho trabajo que supuso la inmersión en uno de los mejores ejemplos de lo que ha dado de sí la educación en nuestro país.

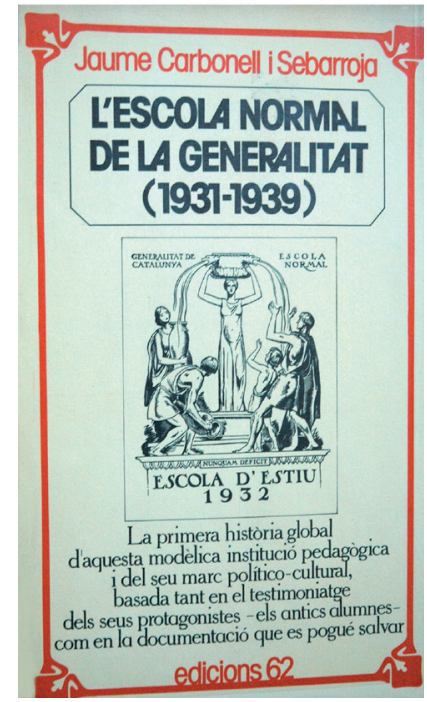

Cubierta del primer libro publicado por Jaume Carbonell sobre la Escuela Normal de la

Generalitat republicana.
A partir de su participación regular en las "Escoles d'Estiu», Jaume Carbonell entra a formar parte del «Seminari d'Història de l'Ensenyament». Según Conrad Vilanou, los antecedentes de este grupo de historiadores "hay que situarlos en torno al año 1970, cuando Jaume Carbonell conoce a Jordi Monés en un curso sobre historia de la educación que impartió en la Escuela de Verano. Un par de años después, el mismo Monés -en un curso que profesó en el ICESB (Institut Catòlic d'Estudis Socials de Barcelona)_entra en contacto con Celia Cañellas, Enriqueta Fontquerni, Esteve Oroval, Mariona Ribalta, Pere Solà y Rosa Toran que asisten como alumnas. Estos contactos - a los que se añadirá, durante un tiempo, Josep González-Agàpito- serán el origen del seminario que, ciertamente, se articuló a modo de un verdadero taller de historia». ${ }^{3}$ Por lo tanto, Jaume, participas en las "Escoles d'Estiu», empiezas a hacer investigación histórica y descubres, en cierto modo, las grandes aportaciones pedagógicas de los siglos XIX y XX.

Efectivamente, a partir de mi asistencia a las Escuelas de Verano, entré

\footnotetext{
${ }^{3}$ Véase: Conrad Vilanou, «Jordi Monés i el Seminari d'Història de l'Ensenyament: Quan la història de la pedagogia esdevé història social de l'educació». Educació i Història: revista d'història de l'educació, 5 (2001-2002): 13-59.
} 
en conocimiento del movimiento de la Escuela Nueva y de sus postulados esenciales: el cuidado, el valor y el protagonismo que se concedía a la infancia. La idea de que los niños y las niñas, desde su nacimiento, son seres sociales, competentes, capaces de mostrarnos lo que todos necesitamos aprender. Y que se educan desarrollando al máximo su propia singularidad al tiempo que se trabaja su acogida, pertenencia y contribución al enriquecimiento de la colectividad. Aún hoy, si cogemos algunos de los 30 puntos de la Escuela Nueva o Activa definidos por Ferrière - no todos, por supuesto-, o las invariantes pedagógicas definidas por Freinet nos daremos cuenta de que son, en conjunto, plenamente vigentes. Por ejemplo, el punto número trece de la declaración de Calais dice textualmente: "La enseñanza se basa sobre los hechos y las experiencias. La adquisición de conocimientos es fruto de observaciones personales o, en su defecto, de las otras recogidas en los libros. La teoría va detrásde la práctica, nunca delante». O el punto veintiuno: «La educación moral, así como la intelectual, se han de ejercer no de fuera a dentro, por autoridad impuesta, sino de dentro a fuera, por la experiencia y la práctica gradual del sentido crítico y la libertad». Por otra parte, mi paso por el «Seminari

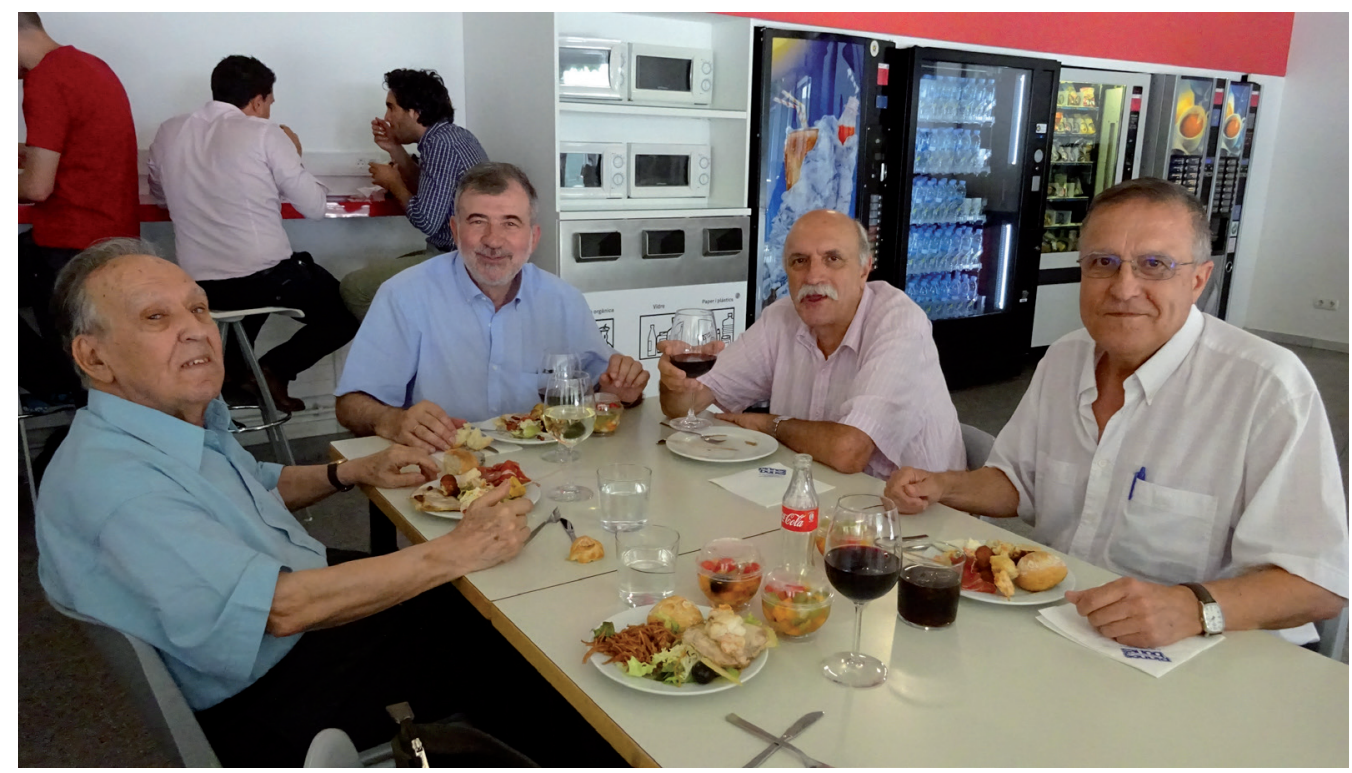

Junto a Anton Costa, Jordi Monés y Antonio Viñao. En Vic, con motivo del XVIII Coloquio de Historia de la Educación, julio de 2015. 
d'Història de l'Ensenyament» supuso para mí la posibilidad de profundizar en la investigación histórica desde una perspectiva extraordinariamente enriquecedora por lo que tenía de espacio de renovación de la historia social y cultural de la educación y la enseñanza, porque vinculábamos la historia con el presente, porque recuperábamos nuestra historia, estudiando personalidades como Ferrer Guardia y Rosa Sensat, iniciativas como el Consell de l'Escola Nova Unificada, instituciones como el Ayuntamiento de Barcelona y la Generalitat republicana, la escuela única, la educación popular, etc. Unos estudios que no he dejado de hacer a lo largo de mi vida...

- A propósito de la historia de la educación del siglo $x \mathrm{X}$ ¿Crees que la renovación pedagógica es "patrimonio de las izquierdas»?, ¿es la "racionalidad instrumental" un paradigma reñido con la renovación pedagógica? ¿Hay algo de error en esto? ¿Hay acentos progresistas en la renovación pedagógica a lo largo del siglo $\mathrm{XX}$ ?

Creo que, en términos generales, la renovación pedagógica en el Estado español, a lo largo del siglo xx, ha sido hegemonizada por un amplia amalgama de fuerzas progresistas: liberales "que no neoliberales», anarquistas, socialistas, comunistas y diversos sectores del socialismo, del cristianismo y del nacionalismo. Basta recordar, a título ilustrativo, la aportación de la Institución Libre de Enseñanza de los Giner y Cossío, la reforma educativa de la Segunda República donde se ensayan las propuestas y metodologías más vanguardistas o las aportaciones de instituciones como «Rosa Sensat», los Movimientos de Renovación Pedagógica (MRPs) y otros colectivos durante el tardofranquismo, la transición y los primeros tiempos democráticos. Se trata, no obstante, de un movimiento heterogéneo que hace suyos los grandes relatos de la pedagogía del siglo xx: Montessori, Decroly, Dewey, Freinet, Freire, Milani,... En todos estos casos se activan procesos que tratan de modificar actitudes, ideas, valores, imaginarios, culturas, contenidos, modelos y prácticas pedagógicas. En todos estos casos adquieren tanta relevancia el qué se enseña como los modos de enseñar y aprender; y casi siempre este proceso apunta hacia una mejora o transformación de la escuela. Otra cosa muy distinta es que en nombre de la Escuela Nueva, de la pedagogía crítica o de la educación libre se cometan todo tipo de disparates o que su carga educativa se vacíe de contenido.

Ahora bien, la renovación pedagógica y, más en concreto, la inno- 
vación educativa -término de origen anglosajón - también han tratado de adueñársela las fuerzas conservadores de talante tecnocrático que, en nombre de la racionalidad técnica y la eficiencia, tratan de modernizar la enseñanza pero nunca de transformarla. Y hoy, existe una enorme retórica en torno a estos conceptos por parte del poder financiero y político dominante, de los «lobbies» privatizadores y de otros agentes que descubren en la innovación la mejor forma para favorecer la competencia individual y el desarrollo macroeconómico, mientras se desnaturalizan y coartan los proyectos personales que se sustentan en la libertad y equidad de los seres humanos, así como los procesos colectivos más democráticos y emancipadores.

Quisiera añadir sobre estas cuestiones que, en ocasiones, como director de la revista y también como persona, nos hemos guiado demasiado por estereotipos y con dicotomías muy maniqueas: pública-privada, educación activa-educación tradicional, ¿no? Pienso que, con frecuencia, hemos sido poco autocríticos con aquellos que eran nuestros referentes. Es evidente que Cuadernos de Pedagogía ha estado siempre al lado y a favor de la escuela pública, pero debemos entender que también este modelo escolar tiene sus miserias. En el fondo, se trata de avanzar en lo que decía mi añorado y admirado amigo Luis Gómez Llorente, que hablaba de la escuela pública como la escuela comunitaria. Hay tres modelos de escuela pública: una escuela pública estatal, dirigida, muy regulada por el poder político; una escuela pública muy corporativa, mediatizada por los maestros, los claustros y el poder docente, y, finalmente, está la escuela pública comunitaria, que se sostiene con la activa participación de la comunidad. En este sentido, personalmente apuesto por una escuela pública que debe garantizar los derechos humanos y, entre ellos, el derecho a una educación equitativa, inclusiva y de calidad; pero también por una institución con mayor autonomía y vertebrada en los territorios locales.

Estoy muy preocupado por el futuro de la escuela pública, aunque pienso que la obsesión excesiva por la dialéctica unidimensional pública-privada no es la mejor vía de análisis y de avance. Dicho de otro modo, como no pienso que a corto plazo podamos acabar con el capitalismo, las voces que apelan a una red única, que oímos en las recientes campañas electorales, son cantos de sirenas sin capacidad de maniobra... En cambio, lo que sí que tenemos que defender son dos 
cosas: una, que la escuela pública no se privatice; es decir, que en los espacios públicos no se privatice nada, algo que se desarrolla en muchos planos: en la gestión, en las concesiones de guarderías, escuelas infantiles, en la concesión de suelo público para la construcción de escuelas privadas. Hay muchas formas de privatización. Se trata, pues, de evitar que se amplíe la escuela privada y de mantener todos los controles necesarios para que la escuela privada que aspire a un concierto educativo, asuma su función de carácter público de verdad. Y, después, lo que tenemos que hacer es fortalecer el modelo de escuela pública, en la línea de lo que hablábamos antes de una escuela comunitaria. La escuela pública debemos hacerla más pública y por lo tanto lo será en la medida que sea más democrática y más participativa. No se trata de seguir reproduciendo miméticamente los Consejos Escolares, que quizás ya no sea una estructura que sirva como sirvió en su momento, sino de explorar y ensayar otras vías de participación democrática. La autonomía es que haya proyectos reales, no proyectos de papel que nadie conoce; proyectos reales con direcciones de centro que se comprometan a hacer los cambios que su comunidad necesite, y que ésta pueda ver en qué se traduce el ejercicio de la democracia...

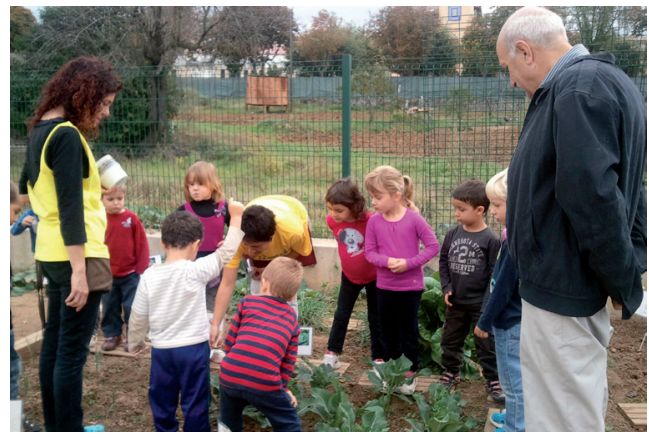

Visitando escuelas. En el huerto del centro «Les Pinediques» de Taradell, (Barcelona).

Creo que debe reivindicarse mucho más el papel del municipio y del pequeño municipio en el desarrollo de una educación pública comunitaria. La posibilidad de una auténtica escuela pública comunitaria se da en territorios pequeños, abordables por parte de los agentes que intervienen y viven en ellos. Unos hablan de la tribu, otros hablan de la ciudad educadora, otros hablan de proyecto formativo integrado o de lo que sea, pero la partida se juega en espacios de participación concretos. Recientemente estuve en una escuela del barrio del Bon Pastor, en Barcelona, en la que desde hace tiempo se trabaja por proyectos. Pues ahora mismo han puesto en pie una universidad del tiempo libre. ¿Y en qué consiste? A partir de la coordinación de una red de seis o siete centros del barrio, han conseguido una implicación de las 
entidades del barrio: de las tres o cuatro bibliotecas, del centro cívico, del centro de documentación histórica, y de otras entidades para ofrecer actividades culturales $\mathrm{y}$ educativas para todo el alumnado, niños y niñas y jóvenes del barrio y eso es básico para estas personas. ¿Por qué? Porque es vital que lo que podemos llamar la «extra-escuela» se enriquezca. Pienso que hoy el derecho a la educación se juega en dos terrenos, en la escuela y fuera de la escuela. Si no se garantiza el derecho a la educación, lo único que se garantiza, y la diferencia no es de matiz, es el derecho a la escolarización, que no es suficiente. El derecho a la educación tiene que ver con las cinco o seis horas que los niños y niñas pasan en la escuela, pero también con las horas que los niños y los adolescentes actúan fuera de los muros o vallas de la escuela. La batalla de la equidad y la igualdad de oportunidades se juega en la familia y en la comunidad; por tanto, yo lo que pienso y cada vez me interesa más, son aquellas políticas educativas y sociales, coordinadas que dan respuestas al conjunto de la población, políticas familiares, de ayudas, políticas que orientan, políticas que no digan si hay que hacer deberes o no, sino que ayuden a hacerlos, con programas de refuerzo y de acompañamiento fuera de la escuela, dentro y fuera de la escuela. Es importante y necesario que el territorio organice su potencial cultural a favor de estos niños y estas niñas, y esto es muy importante. El otro día leía un estudio que sostenía que en la comarca del Baix Llobregat, una de las comarcas trabajadoras más pobladas de Barcelona, existe una clara correlación entre el grado de inclusión social con el nivel del tejido asociativo que tenía este territorio...

- La revista Cuadernos de Pedagogía tiene un largo recorrido de cuarenta años y más de 400 números que se editan con una puntualidad extraordinaria..., todo ello a pesar de la movilidad y los azares empresariales. El profesor José Gimeno Sacristán señala que Cuadernos "ha sido un instrumento que ha vertebrado una amplia comunidad de actores sociales que forman un territorio federado de carácter simbólico común que engloba realidades sociales, humanas y pedagógicas de toda España». Y en relación con esto, Jaume Carbonell en el editorial de su despedida como director de la revista mostraba su agradecimiento y lo hacía recordando que se aprende día a día, en diversidad de contextos y con diferentes personas: "Para mi, el trabajo en la revista ha representado una inmejorable escuela de aprendizaje profesional: del periodismo y de la 
educación, dos campos que siempre se han concebido estrechamente unidos. ¿De dónde he aprendido? De las reuniones de redacción y de corresponsales; de las constantes lecturas de libros, revistas y todo tipo de documentación, de forma solitaria o compartida; de los congresos, jornadas y encuentros informales; de los innumerables viajes por las escuelas de España y de otros países europeos y latinoamericanos; de las muchas horas de observación, escucha y debate; de la propia escritura de notas, artículos y libros; de los

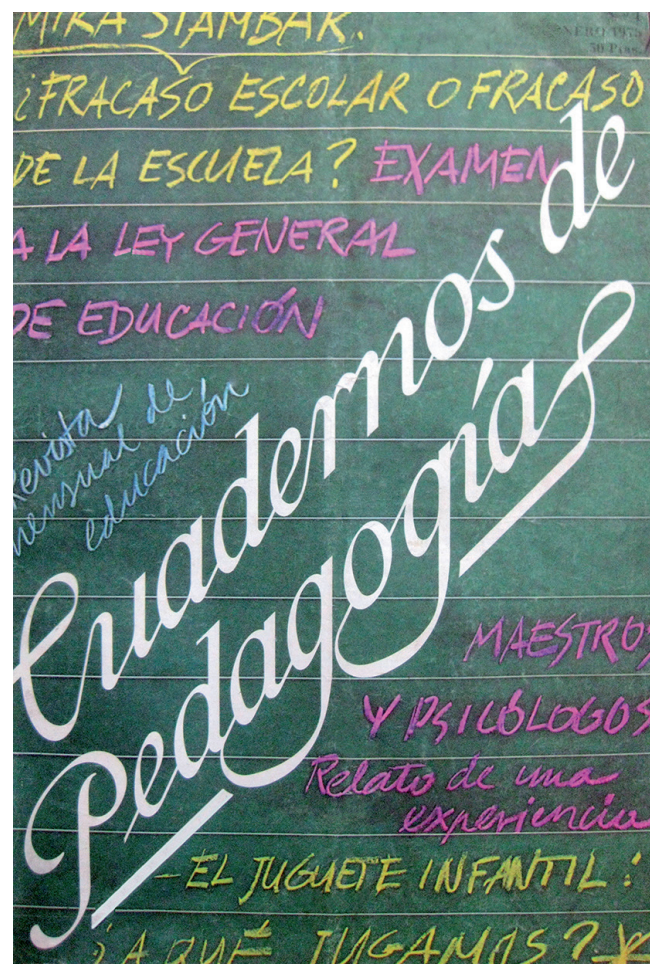

Foto 6. Portada del primer número de Cuadernos de Pedagogía. comentarios o comportamientos del alumnado que, en unos instantes o con pocas palabras, te descubren con lucidez qué está pasando en las aulas, y del profesorado que sabe leer y encauzar los deseos infantiles, (que) no deja nunca de formarse y de preguntarse por qué está haciendo lo que está haciendo o que, a pesar de las múltiples dificultades, no tira nunca la toalla: porque sabe del poder de su intervención para cambiar vidas para siempre». ${ }^{4}$

Jaume, ¿cómo ves la trayectoria de la revista y su papel en la divulgación de la historia del pensamiento pedagógico, de la revisión de la política y reformas educativas, de la difusión de la renovación, innovación y formación del profesorado, de la puesta al día de las prácticas sociales de educación?

Ha sido una apasionante aventura, siempre al servicio de la renovación pedagógica y de una escuela diferente. Ello ha supuesto establecer contacto y conversar con multitud de enseñantes en un ininterrumpido peregrinaje por todos los rincones de España para tomar el pulso de sus preocupaciones cotidianas e ir construyendo un pensamiento educativo crítico y alternativo, le-

\footnotetext{
4 Jaume Carbonell Sebarroja, «Adios y gracias», Cuadernos de Pedagogía, 428 (2012): 3.
} 
jos de estériles dogmatismos y de falaces neutralidades. Trabajando en Cuadernos he aprendido muchísimo, de muchos lugares y de dos cosas: de las lecturas y de las visitas. Yo he aprendido mucho leyendo. A mí, Cuadernos me hizo leer mucho, como me hizo aprender a discutir. Cuando preparábamos un tema, lo discutíamos con la gente; también asistí a bastantes congresos, jornadas; y, en estos entornos se aprende mucho, no sólo dentro del congreso, también en los pasillos y en los bares y restaurantes. En definitiva, para mí supuso un conocimiento extraordinario y apasionante de gente, no citaré nombres, de toda la geografía española... El trabajo en la revista suponía por encima de todo, conocer las escuelas por dentro. Teníamos muy claro el discurso macro y el micro. Con el enfoque macro analizábamos el pensamiento, los valores, la ideología, las relaciones de poder... Pero luego estaban las emociones de los niños, las prácticas concretas, las acciones. Nosotros íbamos a las escuelas. El gran mérito es, creo yo, el haber articulado, práctica y reflexión, trasladando a las páginas de la revista lo que hacían muchos maestros. Me acuerdo de una frase, eso me interesa subrayarlo, de un catedrático de universidad, de pedagogía, que decía «esta revista no puede tener mucho nivel porque participan de- masiados maestros, escriben demasiados maestros». Pues, desde mi punto de vista esta ha sido precisamente la principal virtud de Cuadernos de Pedagogía.

- La triple dimensión profesional de Jaume Carbonell como periodista, educador y sociólogo dificulta su encuadre. En una entrevista en Cuadernos de Pedagogía, Jaume Carbonell escribe: "No me acabo de ubicar entre los pedagogos porque a muchos de ellos el periodismo educativo les resulta un poco extraño, no me reconocen porque Cuadernos está muy alejada de las revistas universitarias más elitistas, que suelen ser reacias a publicar trabajos escritos por maestros. Me siento un tanto heterodoxo pero hasta cierto punto he buscado ese espacio; sé que de muchas cosas no sé nada o muy poco, pero he aprendido a descubrir quién sabe de lo que me interesa saber». ${ }^{5}$

Pues sí, aunque para algunos y aún ahora, Cuadernos es una revista poco valorada porque no es una revista de «impacto» y no es una revista que entre dentro de los cánones de las convenciones académicas. Con lo cual hay profesores que,

\footnotetext{
5 Rafa Miralles, «Aprendo muchísimo con las visitas a las escuelas. Entrevista a Jaume Carbonell», Cuadernos de Pedagogía, 430, (2013): 51.
} 
como quieren hacer currículum, no escriben en ella porque no se puntúa lo suficiente. Y esto es importante decirlo, ¿no?, precisamente porque siendo cierto que Cuadernos de Pedagogía ha sido y es una revista valorada por muchos grandes pedagogos, pensadores y maestros, también ha sido una revista menospreciada, por no hallarse situada en una posición relevante dentro de los parámetros académicos más al uso. En cualquier caso, nosotros hemos intentado crear opinión, hacer evaluación crítica, mostrar resultados de investigaciones, incentivar los análisis, no rehuir polémicas. Nuestra intención bien explícita ha sido la de generar estados de opinión, y hemos intentado generar debate, aunque no siempre lo hemos conseguido; porque debo decir que generar polémica dentro de la educación y la pedagogía no es fácil, no ha sido fácil. Quizás la polémica más conocida es, sin lugar a dudas, cuando se publica el artículo de Mariano Fernandez Enguita, «¿Es pública la escuela pública? ${ }^{6}$, un texto que fue contestado también con intensidad. A mí me pareció muy interesante porque, por primera vez, se rompían apriorismos muy arraigados. Por lo tanto, hemos querido crear opinión

6 «¿Es pública la escuela pública?», Cuadernos de Pedagogía 284, (1999). y hemos querido entrar en el aula. Esto lo hemos tenido siempre presente. Lo hemos hecho siempre y también ahora, gracias a una red de corresponsales que es, simplemente, extraordinaria.

- Cuadernos de Pedagogía nace en enero de 1975. Se estaba implantando la Ley General de Educación (LGE), promulgada cinco años antes. ¿Cómo viviste su puesta en marcha y como lo ves con la distancia que da el tiempo y la evolución de la educación española?

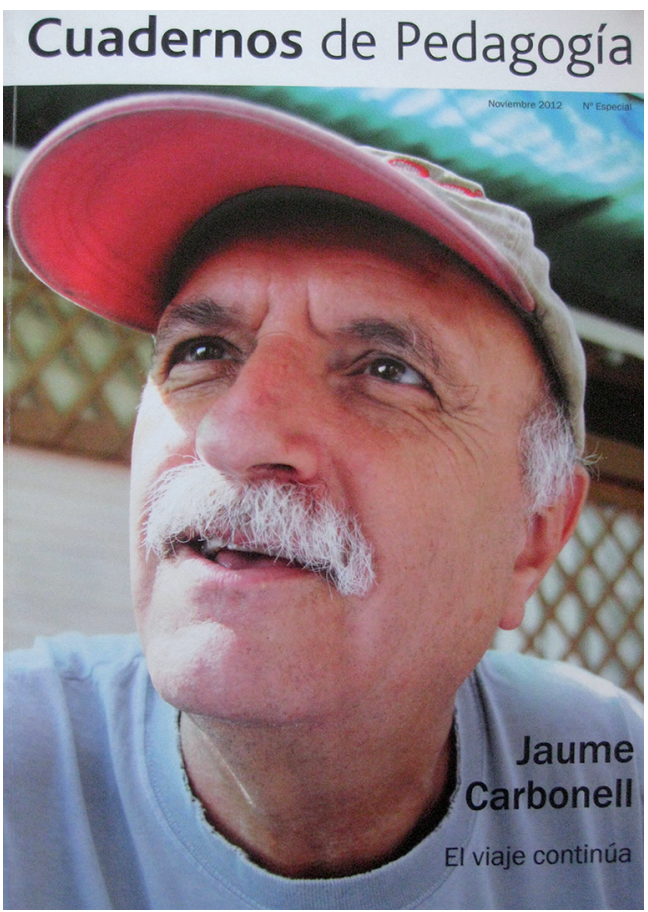

Número Extraordinario de Cuadernos de Pedagogía dedicado a Jaume Carbonell. 
De entrada, vivo la que entonces era una nueva ley educativa desde las barricadas, al militar políticamente en el antifranquismo, pero al mismo tiempo lo vivo como periodista y, por lo tanto, como observador. A mí esta doble perspectiva o dialéctica entre distancia e implicación, me enriquece muchísimo. Visto en perspectiva, me parece que la Ley General de Educación no encajaba del todo en el régimen autoritario en el que nació porque en realidad era una ley moderna $\mathrm{y}$ muy bien hecha, y hasta cierto punto homologable con la de otras reformas educativas europeas. Creo que no ha habido en la historia de España, que yo recuerde, un documento analítico, de diagnóstico, como el Libro Blanco previo a la ley: un análisis panorámico de la educación muy interesante y completo. Lo he echado en falta en las otras reformas, tanto en las del Partido Socialista como en las del Partido Popular. En todas ellas no ha habido un diagnóstico, un análisis a fondo. El Libro Blanco de $1969^{7}$ sigue siendo un documento de referencia. Luego, claro está, una vez promulgada la ley, se comienza a recortar en los decretos de aplicación y sus potencialidades se van

\footnotetext{
7 Ministerio de Educación y Ciencia, La educación en España. Bases para una política educativa (Madrid, 1969).
}

diluyendo. Hay un grave problema de incumplimiento (no sólo en la LGE) en la evolución legislativa de la educación española. Por un lado se promulgan muchas leyes y por el otro se incumplen también muchísimo. La LGE propuso avances como el hecho de alargar la educación hasta los catorce años, con el octavo de Educación General Básica. Pero continúa siendo un sistema selectivo, falta financiación y se incumplen artículos. Por otro lado, hay aspectos interesantes que implican cambios de fondo como el planteamiento de la evaluación continua. Seguramente este cambio fundamental no tuvo una implantación real generalizada pero supuso un avance, sin duda. La supresión de las reválidas es otro aspecto a destacar, y más a la vista de las propuestas involucionistas que en este aspecto se incluyen en la reciente LOMCE [Ley Orgánica para la Mejora de la Calidad Educativa de 2013]. Siempre desde la perspectiva actual, la LGE puede leerse como una ley no propiamente franquista, sino que sería una ley más propia de un estado democrático capitalista, con todos los defectos inherentes a un sistema capitalista.

En cuanto a la LOGSE, estamos también ante una ley emblemática que intenta reestructurar el sistema; por una parte, todo lo que es 
el tramo entre primaria y secundaria, pero también es la entrada de una nueva cultura profesional que sería todo el tema curricular muy dirigido desde la psicología. Es una ley que propone cambios de gran envergadura, y en cualquier caso, el primer gran mérito, indiscutible de la LOGSE es la lucha por el derecho a la educación, la escolarización y la democratización de la enseñanza. Este hecho de que por primera vez se ofrece escuela a todos los alumnos hasta los 16 años, incluso con una cobertura al $90 \mathrm{y}$ pico por ciento en los primeros años, es una conquista indiscutible. Rompe muchos esquemas erróneos y muchos estereotipos, tanto de sectores conservadores, como de gente - mucha de ella, profesores- políticamente de izquierdas, que claramente identifican el derecho a la educación con la disminución de la calidad, de las exigencias y el esfuerzo, con todos los tópicos que conocemos. Es paradójico porque sus referentes son el modelo convencional selectivo, con una gran resistencia a las metodologías innovadoras; una gran resistencia, simplificación y manipulación, que genera una suerte de «desprecio» hacia los profesores que experimentan, que investigan, o que realizan tutorías incansablemente.

A mí me interesa la LOGSE por el hecho que se sitúa en una de las grandes batallas mundiales, uno de los grandes debates, y es que pone en el corazón de la enseñanza el tema de la comprensividad, la inclusión, la educación para todos, con toda la diversidad. Con lo cual se plantea la difícil y compleja ecuación entre equidad y diversidad. Seguramente no siempre la comprensividad se ha explicado bien. Esta idea de que todo el mundo debe tener unos mínimos y debe tener un éxito, pero que los logros son diferentes, por diferentes vías $\mathrm{y}$ a distinto ritmo. Y por tanto, esta idea de decir, todos somos iguales y por lo tanto tenemos el derecho de llegar hasta aquí, pero a la vez, todos somos diferentes y podemos hacerlo de maneras diferentes, a mí me parece muy importante.

\section{- Siempre has tenido una estrecha} relación con Latinoamérica ¿Hasta qué punto las reformas políticas españolas de las últimas décadas actuaron como «espejos» para los países latinoamericanos y con qué grado de acierto?

En mis frecuentes viajes a Latinoamérica, que he recorrido desde México a Argentina, siempre me ha sorprendido la fascinación que se mantiene por «la madre patria». Circunstancia que ha sido muy bien aprovechada por los poderes fácticos políticos y educacionales para 
vender la excelencia de la transición política española, que dista de ser modélica, por lo que ha supuesto la restauración monárquica para abortar algunos derechos de signo social o identitario o para enterrar las políticas de memoria histórica, por citar sólo un par de ejemplos. En el plano educativo parece que hay una lección que, tras el fracaso en la aplicación de muchas reformas educativas, nunca se aprende: que éstas nunca pueden exportarse, ya que son fruto de una época y de un contexto específico. Es posible que en Brasil, Chile o Argentina de algo podría servirles saber de los logros y contradicciones de la LOGSE — de la misma forma que algo podemos aprender nosotros de Finlandia-, pero de ahí a que se intente trasladar mimética y acríticamente nuestro modelo reformista hay un trecho. Afortunadamente, también han emergido voces críticas que han alertado de este nuevo colonialismo promovido por expertos ajenos a sus realidades, y que reivindican el protagonismo del profesorado y de otros agentes educativos en la revisión de su propio sistema educativo. En este sentido, sorprende también muy gratamente el alto y cualificado nivel de investigación y debate que existe en muchos de estos países. Por otro lado, es una temeridad hablar de América Latina como un todo, pues las diferencias entre sus territorios son enormes, debido a las diversas cuestiones antropológicas, culturales, socioeconómicas y políticas.

Las reformas políticas educativas parece como si no se acabaran de implementar nunca, se quedan a medio camino o son inconsistentes a la hora de resolver los grandes problemas de la educación ¿La culpa es del mercado, de la economía, de la incapacidad de los gobiernos que las aplican, de los cambios culturales...? En fin, ¿necesitaremos otra reforma de ley orgánica educativa? ¿Cuáles son las «líneas rojas» de un pacto político con los sectores progresista, conservador y en una España plural desde el punto de vista lingüístico y cultural?

Muchas veces se frivoliza demasiado con decir que tenemos que hacer un pacto de Estado; esto no es nada fácil. Volviendo otra vez a Luis Gómez Llorente, un día hablando con él en su casa, me decía: «fíjate como la LOE [Ley Orgánica de la Educación de 2006], que es una ley que yo he criticado y tu también, puede ser una ley aceptable; tú nunca encontrarás una ley que venga a medida de todos, pero la aceptamos». Hay un aspecto que es muy importante con esto de la democracia; una cosa es la ley que a ti te gusta y otra, la ley que tú acep- 
tas, unos mínimos que tú aceptas, porque con la defensa de la reforma ideal por parte de cada uno, no vamos a ninguna parte. En este sentido, creo que la LOE era bastante homologable a otras reformas europeas y que fue una ley inteligente, con algunas personas clave detrás. Es el caso del entonces secretario de Estado, Alejandro Tiana, que conoce a fondo la política educativa, pero que también conoce la escuela y el mundo académico. La LOE hace unas correcciones interesantes a la LOGSE en relación con el currículo y se alinea con las mejores leyes europeas. De todas formas, creo que un gran pacto educativo no puede ser sólo un pacto de Estado firmado entre los diversos grupos parlamentarios. Para ser sólido y efectivo conviene que el consenso se obtenga también con las diversas organizaciones sociales del ámbito educativo: desde los sindicatos y otros colectivos docentes hasta las AMPA [Asociaciones de Madres y Padres de Alumnos] y otras entidades del mundo educativo. Demasiado a menudo las reformas también fracasan porque los maestros y el conjunto de la comunidad educativa no son escuchados y no se implican en el debate y las

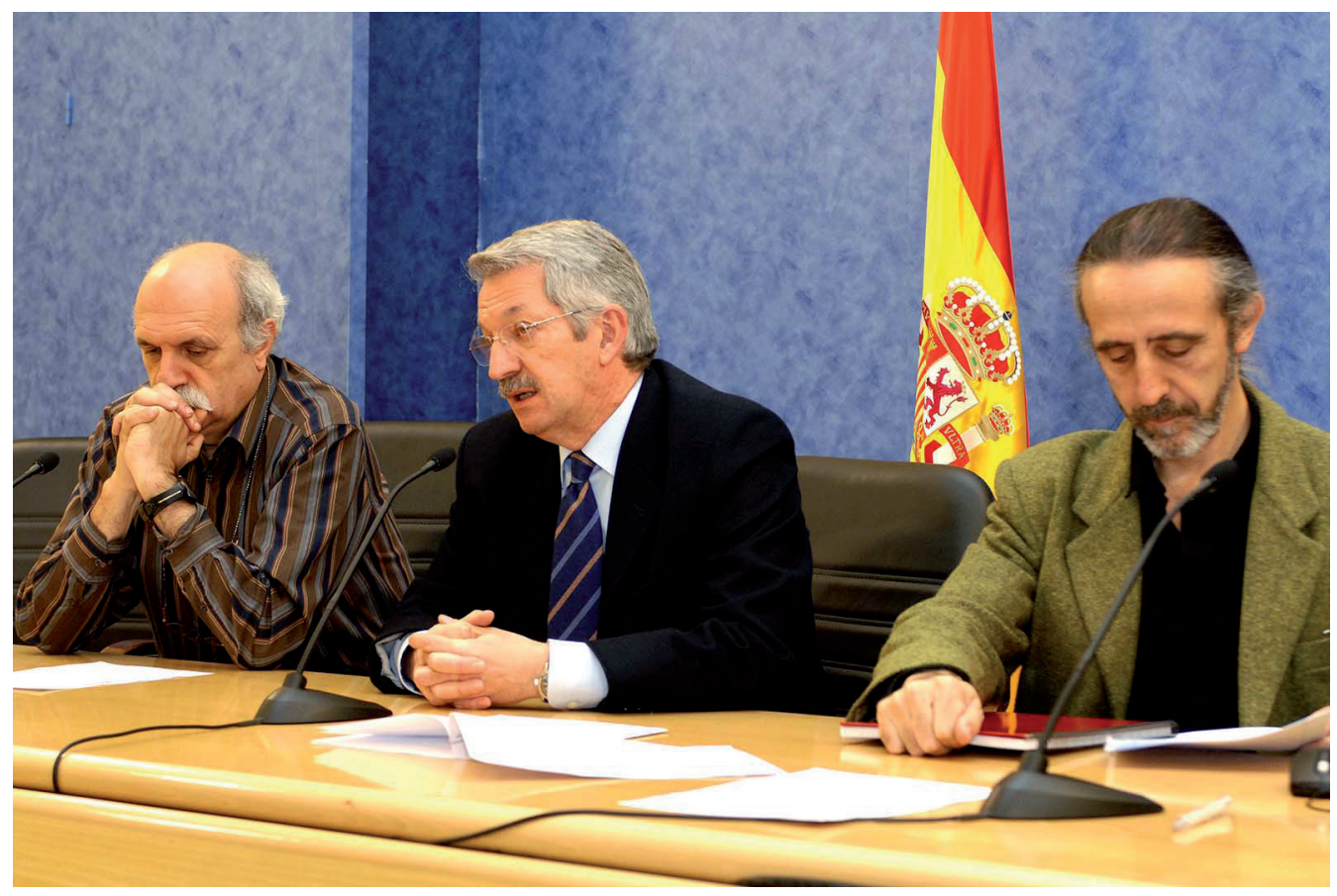

Con Alejandro Tiana y Mariano Fernández Enguita en la Universidad de Santiago, 2007. 
grandes decisiones de política educativa. Otra cosa que no funciona con las reformas, ni con la LOGSE ni con ninguna de las otras leyes, como lo he escrito muchas veces, es que no son reformas educativas, sino reformas escolares que tocan sólo el corazón de la escuela y, por lo tanto, si tú no haces políticas culturales, educativas, de escuela o familiares, te quedas un poco solo en el trabajo del aula y del centro y no son reformas sistémicas.

Siempre has considerado que las reformas curriculares tecnocráticas, uniformes, centralizadas, $y$ "para todos igual», promueven una creciente burocratización de los centros, que están convirtiéndose en "entornos muy artificiales, donde no hay lugar para lo imprevisto». Rechazas una escuela dedicada a resolver problemas urgentes, pero no importantes, que dejan de lado el diálogo sobre los temas de fondo. Por otro lado, las reformas promueven expectativas que no se cumplen, generan «sueños» poco realistas...

Hace poco comentaba con unos estudiantes de Máster hasta qué punto las reformas no deben generar expectativas demasiado ambiciosas. Las reformas marcan unos cambios en las condiciones en cuanto a la escolarización, a la libertad y a la equidad, pero no podemos pensar que los cambios se producen sólo gracias a leyes y cada vez menos. Hay mucha autonomía real de los escenarios micro, con respecto de todo lo macro. Las innovaciones reales, del día a día, del aula, del centro, de estos equipos, pueden producirse por muchos factores. A esto puede ayudar, por ejemplo la formación permanente del profesorado, aunque cada vez menos, porque se ha desmantelado el sistema formativo oficial; por ello, creo que convendría revisar todo el sistema de formación permanente. En segundo lugar, tenemos la influencia de redes civiles organizadas, por ejemplo: los Movimientos de Renovación Pedagógica, como la institución «Rosa Sensat», aunque se trata de un movimiento que yo diría que a nivel general ha decaído, porque no termina de situarse en el momento presente. Luego hay que contar con un tercer ámbito, emergente, como un 15M también en las escuelas, como una revolución silenciosa, que se mueve a nivel horizontal, por la red y que son grupos que se auto-organizan en función de sus intereses, afinidades y complicidades. Cada vez hay más dinámicas no organizadas $\mathrm{o}$ poco organizadas.

En este sentido, siempre me ha apasionado el tema de las transi- 
ciones políticas -en general y en el mundo de la educación- en relación al binomio reforma-revolución, o si se quiere, reforma-ruptura. Me interesan históricamente y también en la actualidad. Un tema emergente que me interesa mucho estudiar ahora y en el futuro es la centralidad-protagonismo del sujeto político de la educación. Éste, antes de la democracia - sobre todo durante la Transición- lo representaban de manera hegemónica los movimientos sociales y educativos con cierto grado de organización. Con la democracia, este protagonismo de los movimientos va decayendo y es sustituido por el Estado con todos sus dispositivos institucionales y formativos. Hoy, de manera incipiente pero progresiva, el sujeto político recae en los movimientos espontáneos no organizados, de carácter horizontal, que reivindican la autonomía y el poder del equipo docente y de unos maestros que, aparte de lo que diga, haga o deje de hacer la Administración, se ponen a caminar y tratan de innovar la institución de manera global o radical, o un ciclo, un departamento, una parcela... Es una nueva forma de ejercer el poder desde la base, de manera muy pragmática, tal vez sin un discurso muy elaborado, aunque en sus acciones hay siempre una reflexión y un cierto pensamiento más intuitivo que elaborado. Estos movimientos se alejan de los dogmatismos aunque hay de todo, pues algunos grupos o personas siguen miméticamente $-\mathrm{y}$, a veces demasiado acríticamente- determinadas propuestas pedagógicas contemporáneas.

- De Jaume Carbonell también cabe destacar su faceta, quizás menos conocida, de docente universitario, como profesor en la Escuela Universitaria de Formación del Profesorado, ahora Facultad, en la actual Universidad de Vic (Barcelona). En su caso, su actividad como docente desborda la del simple profesor asociado o la del ejercicio de un complemento laboral sin más. En realidad, la docencia ha enriquecido su labor como periodista de la educación y, recíprocamente, su actividad en Cuadernos de Pedagogía ha supuesto una fuente de estímulos e iniciativas en beneficio de la docencia universitaria. En 1994, como profesor de la asignatura Sociología de la Educación, Jaume Carbonell publicó La escuela: entre la utopía y la realidad. Diez lecciones de sociología de la educación, un texto en el que el autor procuró compaginar la información rigurosa con una perspectiva histórica, y vincular la teoría con la realidad escolar, una guía para ayudar a ampliar la mirada sobre la escuela de ayer y de hoy, a partir de 
diez grandes temáticas que le parecían especialmente relevantes. Un texto que tiene evidentes fines académicos en la línea de ofrecer una visión panorámica a los estudiantes pero que también tenía una explicita voluntad de interesar al lector que quisiera entender los grandes problemas que la educación tiene planteados.

Jaume, en tu rol de profesor, impulsaste con otros colegas varios proyectos pedagógicos en el marco de la formación inicial del profesorado, como el "T.I.G.R.E». Bajo estas siglas se escondía el "Taller de Iniciación a la Globalización y a la Realidad Educativas", un proyecto global de formación generado a partir de la fusión de los tiempos y espacios de tres asignaturas (Pedagogía, Psicología y Didáctica General) de los estudios de Magisterio. ¿Qué pretendíais con ello? Y desde estas perspectivas que planteabais en Vic ¿cómo ves en la actualidad la formación del profesorado?

Queríamos que la entrada a los estudios para convertirse en maestro no fuera un primer año universitario sin más, sino que pretendíamos ofrecer una auténtica y gran puerta de acceso a todo lo que significa la docencia, con visitas, exposiciones, coloquios, entrevistas con maestras, etc. A su vez, queríamos romper con la fragmentación de los planes de estudio. Se trataba de organizar un contexto educativo flexible y rico en el uso de recursos, materiales, espacios y tiempos con el fin de ayudar a los futuros maestros y a las futuras maestras a analizar la realidad. En definitiva, una propuesta de formación inicial que intentaba romper con la rigidez institucional y flexibilizar el academicismo para hacer pedagogía más allá de los límites de las asignaturas concretas. El hecho de contar con una mañana entera y unas horas de la tarde, suponía que podíamos dar cabida a muchas actividades. Creíamos importante que el estudiante de Magisterio aprenda, como alumno activo, que un mismo contexto de aprendizaje permite muchas y variadas actividades ordenadas a partir de diferentes criterios y que la misma ordenación temporal de las actividades puede modificarse según las necesidades del grupo. No debemos olvidar que estamos hablando de alumnado adulto y, además, hemos de tener en cuenta que el programa de actividades que planeábamos siempre era anunciado con antelación para que los estudiantes pudieran preparar y evaluar las propuestas de actividad y de trabajo.

En realidad, lo que pretendíamos tenía que ver con la concepción profunda de que la formación del 
profesorado debe fundamentarse en tres pilares sólidos e interconectados: contenidos culturales, conocimientos pedagógicos y profesionales y, en tercer lugar, las prácticas. Esta formación debería permitir ampliar la mirada crítica sobre el entorno cercano y lejano, el dominio de los diversos lenguajes, la atención a la más amplia diversidad de alumnos, la innovación educativa en el centro y en el aula, el trabajo colaborativo y una actitud receptiva ante las nuevas realidades y exigencias sociales, culturales y educativas. La clave radica no sólo en el necesario equilibrio entre estos tres pilares, sino también en el grado de conexión constante entre ellos. A menudo, por lo que he observado en mi larga trayectoria como formador de futuros maestros, existe una gran dificultad para transferir lo que los estudiantes aprenden en la universidad en las aulas donde hacen las prácticas, y a la inversa. Se visualizan como dos mundos radicalmente diferentes. Por ello, es muy deseable que se amplíen los períodos de prácticas; y que se configuren como unas prácticas que ayuden a pensar y reflexionar de

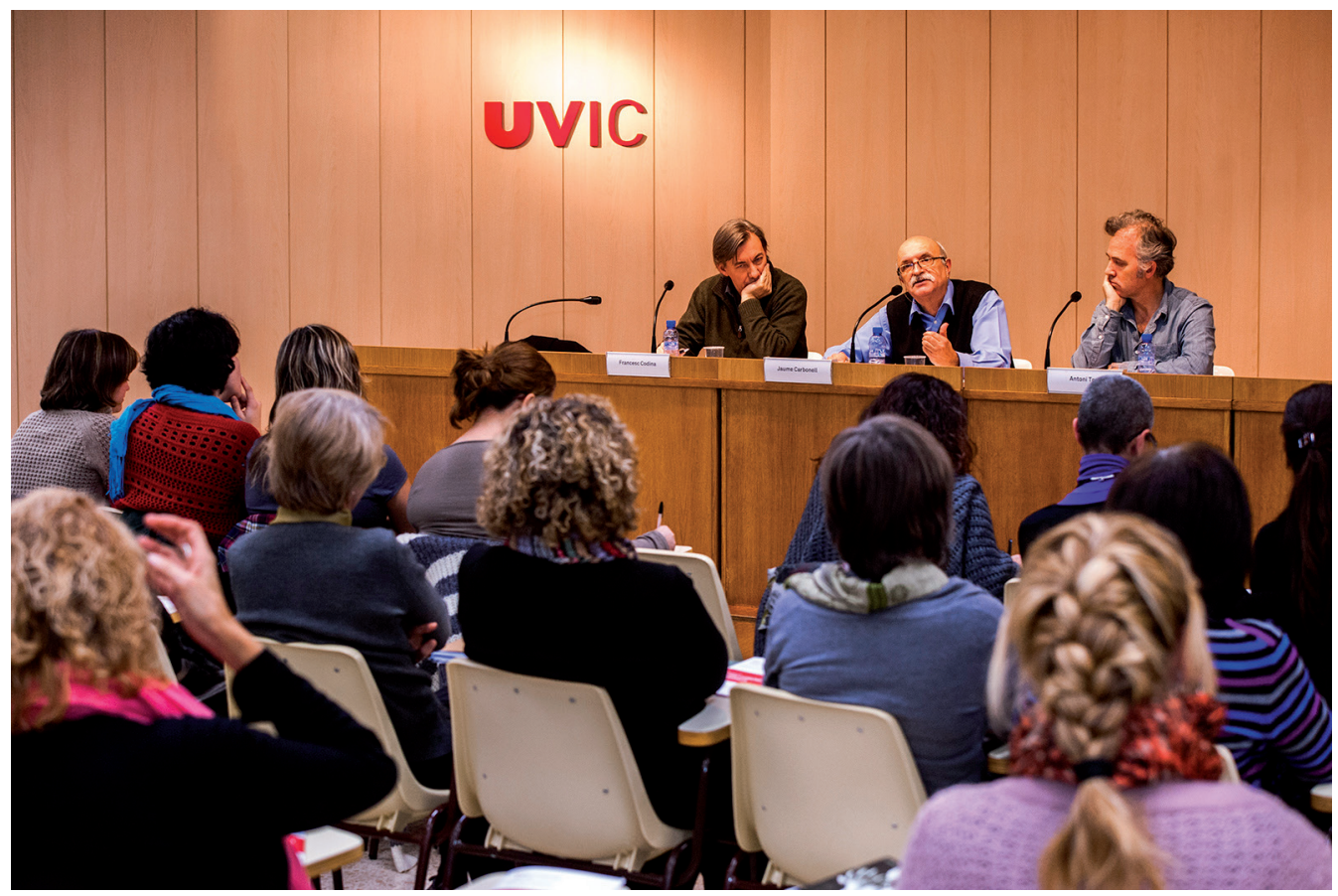

Lección de Jubilación en la Universitat de Vic. 
manera continua, en un proceso en el que la teoría educativa no se vea como un cuerpo extraño alejado, sino como el cemento imprescindible que da consistencia a la vida del centro y del aula.

Siguiendo con el profesorado. Ante el reto de la transformación de las prácticas escolares se percibe una dialéctica entre las dinámicas profesionales de los docentes, que conforman tradiciones más o menos reformadas con el tiempo, y los dictados políticos de las reformas, que son más o menos queridas o malqueridas, llámense LOGSE, LOE, LOMCE. ¿Cómo crees que lo viven los docentes, qué sinergias o, al contrario, qué cortocircuitos se producen en relación a las prácticas en el aula?

Uno de los problemas más graves de las reformas de enseñanza -mal llamadas educativas- de la democracia es que no han ido acompañadas de una propuesta de cambio en la profesión docente. Ahora, sin embargo, parece que se quiere hacer a la inversa o, según como se mire, se quiere responsabilizar al profesorado de todo lo que pasa en nuestra educación. Es una obviedad, y el ejemplo finlandés está en boca de todos, afirmar que los maestros son una pieza clave para garantizar la calidad de la enseñanza. Pero no la única. Y los cambios que han tenido éxito en nuestra historia (hay que recordar las reformas de la Segunda República y las de otros países) son aquellos en los que se ha planteado un cambio sistémico que afecta a la totalidad de las piezas que conforman el sistema educativo: objetivos y valores; currículo, organización, autonomía y gestión democrática de los centros; relaciones educativas entre los diferentes agentes; tiempos y espacios; papel de la dirección de los centros y de la inspección; derecho a la educación e igualdad de oportunidades; relación de la escuela con la comunidad y con las diferentes políticas sociales y culturales... Hoy, además, convendría situar la escuela en los procesos de cambio acelerado en la sociedad del conocimiento y en los contextos de aprendizaje y formación, cada vez más amplios e influyentes, que tienen lugar fuera de la escuela. En el capítulo de formación del profesorado se invirtió mucho dinero y, con frecuencia, incluso se derrochó. Porque no hubo evaluaciones sobre las mejores modalidades formativas, se daban a veces palos de ciego o se lanzaban propuestas sin tener claro el encaje legal de los futuros formadores. No hubo, por tanto, un debate sobre qué tipo de formación se requería para un profesorado innovador que contribuyera a la mejora o transformación del pro- 
ceso de enseñanza y aprendizaje. La deficiente formación inicial y permanente fue, a la postre, una de las mayores debilidades durante el proceso de aprobación y desarrollo de la LOGSE, lo que, por tanto, dificultó en buena medida la calidad de la enseñanza. Sin lugar a dudas, uno de los grandes logros de la LOGSE fue la regulación de la ESO [Enseñanza Secundaria Obligatoria] hasta los 16 años dentro de un modelo comprensivo que, al propio tiempo, garantizaba la atención a la diversidad. Un modelo que en otros países europeos había configurado un sistema de oportunidades más equitativo para todo el alumnado. Pero, es evidente que escolarizar al cien por cien de la población, con todas sus diversidades y problemáticas, supone un compromiso sólido y sostenido por parte no sólo de la Administración sino de toda la comunidad educativa. Y por parte del profesorado requería una intervención y tutorización intensiva para aplicar las necesarias adaptaciones curriculares, actividades de refuerzo y otro tipo de medidas de compensación escolar o de discriminación positiva para el alumnado de origen social y cultural más desfavorecido, o que presentaba especiales déficits académicos o de adaptación. Pero ni la Administración explicó suficientemente a la comunidad lo que supo- nía aceptar el reto de la comprensividad, en una sociedad fuertemente segmentada, individualista y competitiva, ni se formó al profesorado adecuado para hacerla efectiva.

Hay que tener en cuenta, además, que el grueso de los enseñantes que se ocuparon y se ocupan aún de esta etapa son los antiguos profesores de bachillerato, acostumbrados a enseñar a una selección de estudiantes procedentes mayoritariamente de las clases medias y a funcionar dentro de un sistema altamente segregador y selectivo, donde la tutoría, el acompañamiento, la recuperación y otro tipo de medidas relativas a la inclusión escolar, y a la atención a la diversidad, son sistemáticamente ignoradas y ninguneadas. Para ellos lo importante era limitarse a enseñar la asignatura sin implicarse demasiado en averiguar si aprendían o cómo aprenden o podrían aprender mejor sus alumnos y alumnas, y sin entrar en estas «lindezas» de la educación en valores y para una ciudadanía democrática. Este corporativismo docente, atizado sobre todo por una parte del escalafón de los catedráticos, frustró buena parte de las esperanzas depositadas en la comprensividad. Dicho lo cual, faltaríamos a la verdad si no mencionáramos las buenas prácticas y el buen hacer de 
un profesorado que, aunque demasiado minoritario, ha puesto de relieve las potencialidades de la enseñanza comprensiva para avanzar hacia el logro del éxito escolar de todo el alumnado. En realidad, no se profundizó en qué son las culturas profesionales y se hizo una diseminación de la formación muy vertical, con sesiones en las que se dictaba lo que se tenía que hacer en las aulas. Una de las críticas que se puede hacer a la estructura curricular que se planteaba en la LOGSE es que se partía de un marco muy interesante, pero que se planteó con una gran rigidez. Yo creo que debería haber mucha más experimentación antes de aplicar determinados postulados. Lo mismo sirve para las propuestas que ahora proponen una especie de MIR [Médico Interno Residente: sistema de formación de especialistas médicos implantado en España en 1978] para el profesorado ¿Por qué no se experimenta antes?

- Recientemente comentaste que «La utopía educativa es posible en pequeñas dosis y espacios». En calidad de testigo y actor de la renovación pedagógica y del clima de innovaciones didácticas, ¿cómo se podría valorar lo sucedido en estas cuatro décadas? ¿En qué momento estaríamos desde el inicio del siglo XXI y hacia dónde vamos?
Creo que se ha producido una evolución muy significativa. Una progresión cuantitativa y cualitativa, aunque no lineal. Por un lado, tenemos un contexto socioeconómico y cultural con grandes transformaciones en los modos de producción, en la organización del trabajo, en las formas de relación y de socialización. También hay un tipo de mutaciones relacionadas con la investigación y el progreso científico que enriquecen el campo de la educación con aportaciones cada vez más valiosas desde disciplinas tan diferentes como la neurociencia, el pensamiento sistémico, los estudios culturales, la perspectiva de género, el urbanismo... Unas mutaciones que están ampliando la mirada sobre la educación, haciéndola más compleja, con nuevos datos, evidencias e interpretaciones. La concepción del carácter marcadamente multidimensional de las inteligencias es un ejemplo de ello. Estos cambios y avances obligan a replantear qué entendemos por conocimiento y conocimiento escolar. ¿A partir de qué criterios y evidencias se puede considerar que un conocimiento es científico, riguroso, fiable, significativo, básico, útil? Y a continuación cabe preguntarse cuáles son los procesos, las estrategias de la enseñanza-aprendizaje capaces de responder a los retos planteados. En cualquier caso, las metodologías pueden ser múl- 
tiples pero, lo que es cada vez más determinante es la cantidad, y sobre todo la calidad, de las interacciones entre maestros y alumnos. Porque la educación del futuro precisa cada vez más del diálogo y conversación: para compartir saberes y aclarar dudas, para despertar el deseo de aprender y la curiosidad hacia el conocimiento, y para establecer los vínculos y complicidades necesarios para una auténtica comunidad de aprendizaje.

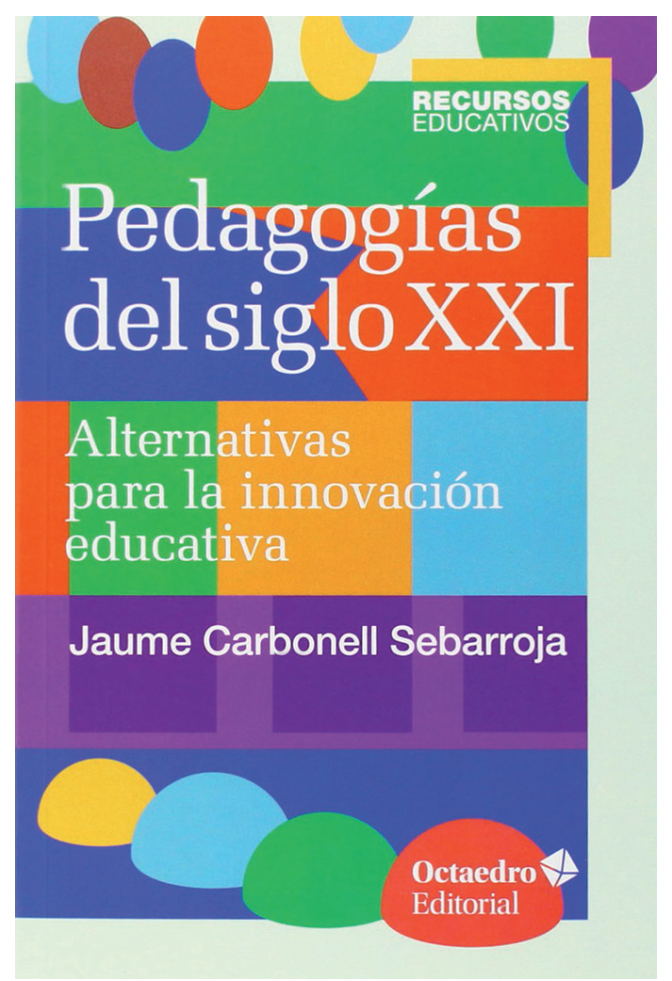

Cubierta de su último libro Pedagogías del siglo XXI. Alternativas para la innovación educativa (Barcelona: Octaedro Editorial, 2014).
Otro aspecto central de las últimas décadas es la mejora en relación con las políticas sociales y educativas para facilitar el éxito escolar de los niños y niñas socialmente más vulnerables. El derecho a la educación para todos - la igualdad y equidad educativas - se compagina con la aceptación creciente de todo tipo de diferencias: sociales, culturales, lingüísticas, sexuales, de creencias... La escolarización de muchos alumnos considerados diferentes antes se hacía en instituciones o espacios específicos, mientras que hoy se hace en la escuela ordinaria.

Es una gran conquista que no se ha culminado aún en muchos momentos y en muchas partes del mundo. Finalmente, conviene señalar el protagonismo creciente de la educación fuera de la escuela, que modifica la función original de transmisión del saber, porque los escenarios de instrucción y socialización se diversifican. Se incrementan las conexiones entre personas y nuevos artefactos; la ciudad se convierte en un libro abierto con una oferta creciente de actividades formativas y de intercambios; se impone la llamada educación expandida, entre lo no formal y lo informal. Estas son algunas de las características y de los retos de nuestro mundo y, en 
consecuencia, de nuestras formas de educar.

Centrándonos más en la educación escolar, creo que en Cataluña y España la gente se ha cansado un poco de esperar que las leyes o la administración les ayuden a solucionar los problemas, o les animen a impulsar cambios profundos. Es decir, hay un distanciamiento o incluso una desafección hacia el funcionamiento habitual de la política educativa, hacia la administración educativa y todo su cuerpo legal reformista. El profesorado quiere llevar a cabo sus propios proyectos pedagógicos sin necesidad de la autorización o la aquiescencia de los administradores. Es como una revolución silenciosa que a través de muchas redes virtuales y presenciales, a menudo poco organizadas, se va extendiendo como una mancha de aceite por escuelas y territorios. Creo que se podrían establecer ciertas similitudes con el momento político que vivimos de desafección en relación a los gobiernos... En cualquier caso, se desconfía de políticas educativas burocratizadas, de administraciones y, en ocasiones, de los sindicatos. Maestros y maestras se plantean cómo innovar. La dialéctica de este profesorado no es la de plantearse qué da o qué no da la administración, el hecho de si la administración cumple o no cumple, sino que se dicen ellos mismos: nosotros somos gente que estamos preparada, vocacional y comprometida y somos gente que tenemos convicciones, somos creativos y nos montamos la vida y si no podemos comprar este material lo podemos reciclar, ¿no?, y si no podemos pagar una persona, cogemos un voluntario que cobrará menos..., y se espabilan con la ayuda del AMPA, etc., Activan mecanismos nuevos, desestructuran espacios y tiempos en una dinámica muy creativa y muy participativa. Se crean redes de relación horizontal sin pasar por las administraciones. En definitiva, creo que en relación a la innovación educativa, muchos maestros y maestras asumen de forma clara y radical su autonomía profesional y perciben que pueden poner en marcha las propuestas pedagógicas que creen convenientes e ilusionantes sin tener que supeditarse a lo que dictamine el aparato administrativo del sistema educativo. Estamos ante el viejo debate sobre si el poder reproduce y si el poder lo controla todo, o si la agencia humana, si la gente, puede empoderarse por utilizar un verbo de moda. La realidad es que, en estos momentos, dentro de la estructura escolar hay muchas rendijas, hay muchas ventanas, y los maestros y las maestras las están aprovechando. 


\section{SELECCIÓN DE OBRAS DE JAUME CARBONELL SEBARROJA}

- L'Escola Normal de la Generalitat: 1931-1939 (Barcelona: Edicions 62, 1977; reed. en 1993, con prólogo de Marta Mata).

- (con Jordi Monés) L'Escola única-unificada (Barcelona: Laia, 1978).

- «Prólogo», en Nadeshda Krupskaia, La Educación comunista: Lenin y la juventud (Madrid: Nuestra Cultura, 1978).

- (con Luis Miguel Lázaro, Jordi Monés y Pere Solà) Ferrer Guardia y la pedagogía libertaria: elementos para un debate (Barcelona: Icaria, 1980).

- (con Fabricio Caivano) Antón Makarenko: una antologia (Madrid: Nuestra Cultura. 1981).

- (con Fabricio Caivano) 15 personajes en busca de otra escuela (Barcelona: Laia, 1984).

- Manuel Bartolome Cossio. Una antología (Madrid: Ministerio de Educación y Ciencia, 1985).

— «Introducció», en John Dewey, Democràcia i escola (Vic: EUMO, 1985; ed. en español, Madrid: Popular, 2009).

- (con Ricard Torrents, Antoni Tort y Jaume Trilla) Els grans autors i l'escola (Vic: EUMO, 1987).

- (con Antoni Tort) «Pròleg», en Neil Postman, La desaparició de la infantesa (Vic: EUMO, 1989).

- La reforma educativa a lo claro (Madrid: Editorial Popular, 1989).

- Aprendiendo de las innovaciones en los centros. La perspectiva interpretativa de investigación aplicada a tres estudios de caso (Madrid: CIDE/MEC, 1994; reed. En Octaedro en 1998 y en Artmed, Brasil, en 2000).

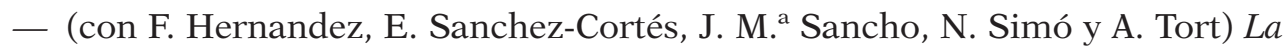
escuela: entre la utopía y la realidad: diez temas de sociología de la educación (Barcelona: Octaedro, 1996).

- La aventura de innovar: el cambio en la escuela (Madrid: Morata, 2002).

- (con José Gimeno Sacristán, coords.,) El sistema educativo: una mirada crítica. (Barcelona: Ciss Praxis, 2004).

- (con Núria Simó y Antoni Tort) Magrebies en las aulas. Municipio, escuela e inmigración: un caso a debate (Barcelona: Octaedro, 2005).

- (con Antoni Tort) La educación y su representación en los medios (Madrid: Morata, 2006). 
- (con Isabel Carrillo) Formación y cooperación. Una experiencia de prácticas de educación en Centroamérica (Barcelona: Octaedro, 2007).

- (con Antoni Tort) L'educació catalana a la prensa (Barcelona: Fundació Bofill, 2008).

- Una educación para mañana (Barcelona: Octaedro, 2008).

- (con Àngel Serra) La vida escolar en un curso. Cosas que no siempre se explican (Barcelona: Graò, 2009). Coautor con Àngel Serra.

- Viaje por las escuelas de Cantabria (Madrid: Wolters Kluwer, 2009).

- Viaje por las escuelas de Aragón (Madrid: Wolters Kluwer, 2010).

- Viaje por las escuelas de Asturias (Madrid: Wolters Kluwer, 2011).

- Pedagogías del siglo XXI: alternativas para la innovación educativa (Barcelona: Octaedro, 2015).

\section{Nota sobre los autores:}

Antoni Tort Bardolet (Manlleu, Barcelona,1958) es Doctor en Pedagogía y premio extraordinario de doctorado por la Universitat de Barcelona. Actualmente compagina la docencia y la investigacióncomo profesor titular con la Dirección de la Escuela de Doctorado en la Universitat de Vic-UCC, de la que ha sido decano de su Facultad de Educación durante siete años. Es coordinador del GREUV (Grup de Recerca Educativa de la UVIC), grupo cuyas últimas investigaciones versan sobre «educación, territorio y comunidad», «interculturalidad y educación», «relación familias-escuela» y «patrimonio educativo», entre otros temas. Dirige la colección, de más de cincuenta títulos, «Textos Pedagògics» de EUMO editorial que publica en lengua catalana los grandes autores de la pedagogía de todos los tiempos. En 1996, obtuvo el Premio «Josep Pallach» de pedagogía, con su obra: Opinions públiques sobre l'educació. Tiene numerosas publicaciones en forma de artículos y libros, de ámbito nacional e internacional. Su última publicación es un capítulo en la obra colectiva Vint mestres i pedagogues catalanes del segle XX. Un segle de renovació pedagògica a Catalunya, editado por la Asociación «Rosa Sensat», y tiene en prensa la publicación, como coautor i coeditor, de la obra Gobernanza Escolar Democrática, de próxima aparición en Ediciones Morata. 
Antón Costa Rico es Catedrático de Historia da Educación en la Universidade de Santiago de Compostela. Con trayectoria docente e investigadora en los campos de la política educativa y de la historia da educación. Es uno de los fundadores del movimiento de renovación pedagógica Nova Escola Galega, del cual es militante activo, con intervención en foros estatales de estos movimientos. Ex-director del ICE de la Universidad de Santiago y ex-decano de la Facultad de Ciencias de la Educación. Fue presidente de la SEDHE. Director de catorce tesis doctorales y con presencia académica en diversos países de Europa y de Iberoamérica. Fue asesor de Cuadernos de Pedagogía desde Galicia y es miembro de los consejos de redacción de Revista Galega de Educación y de Sarmiento.

Entre sus obras: O ensino en Galicia (1980), Escolas e mestres (1989), Historia do ensino no Reino de Galiza (anos 413-1483) (1995), A reforma da educación (1906-1936) (1996), Informe sobre a situación e estado do sistema educativo en Galicia (1995; Dir. de Informe), Fray Martín Sarmiento. La educación de la niñez y de la juventud (en colaboración) (2002), Historia da educación e da cultura en Galicia (2004), A construción do coñecemento pedagóxico Antecedentes e desenvolvementos no século XX (2009), Luis Bello. Viaje por las escuelas de Galicia (2010), D'abord les enfants. Freinet y la educación en España (1926-1975) (2010). Recibió diversos reconocimientos, el más reciente el Premio Internacional 2014 del CIRSE. 